\title{
Obstructive sleep apnea syndrome should be considered as a cause of nocturia in younger patients without other voiding symptoms
}

\author{
Takahiro Maeda, MD,; Koichi Fukunaga, MD, PhD; Hirohiko Nagata, MD; ${ }^{; *}$ Mizuha Haraguchi, MD; \\ Eiji Kikuchi, MD;' Akira Miyajima, MD,' Wakako Yamasawa, MD,2 Ryutaro Shirahama, MD, ${ }^{3}$ \\ Midori Narita, MD,-4 Tomoko Betsuyaku, MD, Koichiro Asano, MD,; Mototsugu Oya, MD'
}

'Department of Urology, Keio University School of Medicine, Tokyo, Japan; 'Division of Pulmonary Medicine, Department of Internal Medicine, Keio University School of Medicine, Tokyo, Japan; ${ }^{3}$ Good Sleep Clinic, Tokyo, Japan; "Shibuya Sleep Medical Clinic, Tokyo, Japan

*Equal contributors

Cite as: Can Urol Assoc J 2016;10(7-8):E241-5. http://dx.doi.org/10.5489/cuaj.3508 Published online July 12, 2016

\section{Abstract}

Introduction: This study aimed to evaluate urination frequency among patients with obstructive sleep apnea syndrome (OSAS) and the effect of continuous positive airway pressure (CPAP) treatment. Methods: We evaluated 138 men with moderate-to-severe OSAS by using polysomnography. Urination status was assessed at baseline and three months using the International Prostate Symptom Score and Overactive Bladder Symptom Score. Nocturia was defined as $\geq 2$ nighttime urinations and patients were classified into Group A $(<50$ years old with nocturia), Group B ( $\geq 50$ years old with nocturia), and Group C (patients without nocturia). OSAS severity and other urinary symptoms were also evaluated.

Results: Patients with nocturia exhibited more severe OSAS, compared to patients without nocturia (apnea-hypopnea index [AHI]: 52.0 vs. 44.7; $p=0.021$ ). Group $A$ had the worst $A H I$, but did not have additional voiding symptoms, compared to Group B $(p<0.001)$. The number of urinations was significantly correlated with OSAS severity in $<50$-year-old patients $(p=0.013)$. CPAP reduced the number of urinations in Group $A$ ( $75 \%$ of patients) and Group B (90\% of patients). Patients with and without improved nocturia exhibited significant differences in their baseline OSAS severity (AHI: 53.7 vs. 37.3; $\mathrm{p}=0.042$ ).

Conclusions: OSAS severity was associated with the number of urinations in $<50$-year-old patients. CPAP decreased the nocturia frequency in $85 \%$ of patients with nocturia and was most effective in patients with severe AHI. However, additional studies should evaluate voiding volume in order to elucidate the mechanism of nocturia in patients with OSAS.

\section{Introduction}

Obstructive sleep apnea syndrome (OSAS) causes sleep deprivation-induced symptoms (e.g., daytime sleepiness) and indirectly induces systemic symptoms, such as hypertension $^{1,2}$ and impaired glucose tolerance. ${ }^{3,4}$ Many studies have demonstrated that OSAS should be diagnosed and treated at an early stage, ${ }^{5,6}$ because OSAS can cause serious traffic accidents, ${ }^{7}$ long-term hypoxic stress, ${ }^{8}$ a pro-inflammatory state, ${ }^{9}$ and endothelial dysfunction ${ }^{10}$ in various organs. Although some patients with undiagnosed OSAS may visit an otolaryngology department to be treated for their snoring, other patients may visit a psychiatry department for a sense of malaise or a urology department for nocturia or erectile dysfunction. As OSAS generally induces vague and non-quantitative symptoms, it is difficult for patients and their doctors to determine that OSAS might be the cause of their symptoms. Therefore, it is likely that many people with OSAS remain undiagnosed. ${ }^{11,12}$

Nocturia is another multifactorial disorder that can be caused by hypertension, diabetes, heart failure, or sleeping disorders. ${ }^{13,14}$ OSAS can be an underlying cause of nocturia, although it is infrequently recognized, even in the field of urology. However, waking to urinate is an easily noticed and quantitative variable. Therefore, we hypothesized that its frequency could facilitate the early detection of OSAS in patients with frequent nocturia. The present study aimed to investigate the prevalence of nocturia among patients with newly diagnosed moderate-to-severe OSAS. We also assessed the correlation between various patient characteristics and urinary status, and evaluated the efficacy of continuous positive airway pressure (CPAP) for treating nocturia in patients with OSAS. 
Maeda et al.

\section{Methods}

This study prospectively recruited 150 men who planned to receive CPAP for moderate-to-severe OSAS (an apneahypopnea index [AHI] of >15) between 2009 and 2011 at affiliated institutions in Japan. The study's design was approved by the institutional review board at each clinic, and all patients provided their informed consent to participate. Among the 150 patients, 12 patients were excluded because they did not complete the study's questionnaire. We also excluded patients who were receiving diuretic medication, patients with inadequately controlled diabetes mellitus, and patients with symptomatic heart failure, renal failure, or urinary infection. OSAS was diagnosed via overnight polysomnography (PSG for $\geq 6$ hours) at the sleep clinic; apnea was defined as the termination of respiratory airflows for $\geq 10$ seconds and hypopnea was defined as a $\geq 50 \%$ decrease in ventilation that was accompanied by a $\geq 3 \%$ decrease in oxygen saturation. AHI was defined as the number of instances of apnea and hypopnea per one hour (while sleeping); moderate or severe OSAS were defined as an $\mathrm{AHI}$ of $15-29$ or $\geq 30$, respectively. ${ }^{15}$

Urinary status was assessed at baseline and three months after the CPAP treatment, using the International Prostate Symptom Score (IPSS) and the Overactive Bladder Symptom Score (OABSS). ${ }^{16} \mathrm{We}$ also measured the number of nighttime urinations using Question 7 from the IPSS questionnaire; nocturia was defined as $\geq 2$ urinations in a single night. Voiding status was calculated as the sum of the scores for Questions 1, 3, 5, and 6 from the IPSS questionnaire, and storage status was calculated as the sum of the scores from Questions 2, 4, and 7.

Patients were classified into three groups based their age and nocturia status. Group A included patients with nocturia who were $<50$ years old, Group B included patients with nocturia who were $\geq 50$ years old, and Group C included

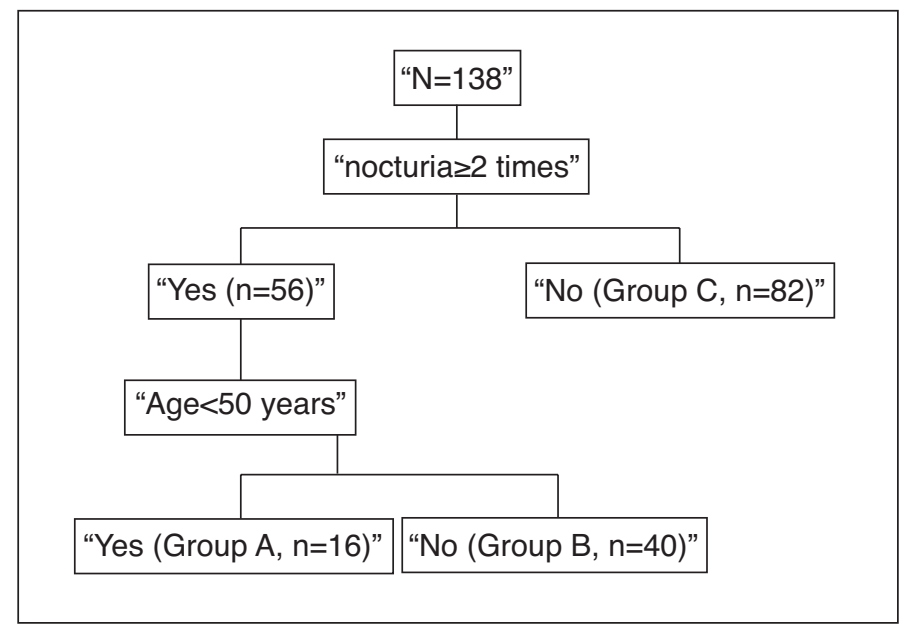

Fig. 1. Study flow chart. patients who did not have nocturia (Fig. 1). Using these groups, we assessed the association between OSAS severity and the patients' characteristics, as well as the efficacy of CPAP treatment for nocturia in each group.

Results were presented as mean \pm standard deviation. Differences in nocturia and the IPSS voiding score (baseline vs. three months after CPAP treatment) were analyzed using the Wilcoxon-signed-ranks test, and differences in continuous characteristics were analyzed using the MannWhitney U-test. The correlation between nocturia status and the severity of OSAS was analyzed using Spearman's rank correlation test. All $p$ values were two-sided and a $p$ value of $<0.05$ was considered statistically significant. All analyses were performed using JMP software (version 10.0.2; SAS Institute, Irving, CA, U.S.).

\section{Results}

\section{Urination status before CPAP treatment}

The mean patient age was 53.8 years (range 21-83 years) and the mean body mass index (BMI) was $27.2 \mathrm{~kg} / \mathrm{m}^{2}$ (range $\left.19.7-38.5 \mathrm{~kg} / \mathrm{m}^{2}\right)$. Before the CPAP treatment, the average AHI was $47.7 \pm 19.4$ (range 17.7-99.0), 110 patients exhibited severe OSAS (an AHI of $\geq 30$ ) and 28 patients exhibited moderate OSAS. The average number of nighttime urinations, total IPSS, and OABSS at baseline were $1.4 \pm 1.3$ (range 0-5), $6.0 \pm 6.4$ (range 0-34), and $2.7 \pm 2.6$ (range $0-13$ ), respectively (Table 1 ). The prevalence of nocturia was 40.6\%; Group A included 40 patients, Group B included 16 patients, and Group $C$ included 82 patients. Compared to patients with OSAS and without nocturia (Group C), patients with OSAS and nocturia (Groups A and B) tended to be significantly older $(57.8 \pm 12.3$ years vs. $50.9 \pm 11.9$ years; $\mathrm{p}<0.01$ ) and to have significantly more severe OSAS (AHI: $52.0 \pm 19.1$ vs. $44.7 \pm 19.1 ; p=0.021$ ) (Table 2 ). The number of nighttime urinations was not correlated with OSAS severity in the entire patient population (correlation

\begin{tabular}{|c|c|c|c|}
\hline & Before CPAP & After CPAP & p value \\
\hline Nocturia (times) & $1.4 \pm 1.3$ & $0.7 \pm 0.9$ & $<0.01$ \\
\hline \multicolumn{4}{|l|}{ IPSS } \\
\hline Total score & $6.0 \pm 6.4$ & $4.3 \pm 5.1$ & $<0.01$ \\
\hline Voiding score & $2.9 \pm 4.2$ & $2.3 \pm 3.5$ & $<0.01$ \\
\hline Storage score & $3.1 \pm 2.9$ & $2.0 \pm 2.1$ & $<0.01$ \\
\hline OABSS score & $2.7 \pm 2.6$ & $1.7 \pm 1.7$ & $<0.01$ \\
\hline $\begin{array}{l}\text { Patients } \\
\text { with urgent } \\
\text { incontinence }\end{array}$ & 12 & 6 & \\
\hline
\end{tabular}




\begin{tabular}{|c|c|c|c|}
\hline & Group A & Group B & Group C \\
\hline $\begin{array}{l}\text { Number of } \\
\text { patients }\end{array}$ & 16 & 40 & 82 \\
\hline Age, years & $43.6 \pm 3.9$ & $63.7 \pm 9.3^{a}$ & $50.9 \pm 11.9^{c}$ \\
\hline $\mathrm{AHI}$ & $62.0 \pm 18.9$ & $47.8 \pm 17.9^{b}$ & $44.7 \pm 19.1^{d}$ \\
\hline \multicolumn{4}{|l|}{ IPSS } \\
\hline Total score & $4.6 \pm 1.8$ & $11.6 \pm 7.5^{\mathrm{a}}$ & $3.5 \pm 4.4^{c}$ \\
\hline Voiding score & $0.7 \pm 1.1$ & $5.4 \pm 5.3^{a}$ & $2.0 \pm 3.3^{c}$ \\
\hline $\begin{array}{l}\text { Number of } \\
\text { urinations }\end{array}$ & $2.6 \pm 0.8$ & $2.9 \pm 0.9$ & $1.4 \pm 1.4^{c}$ \\
\hline \multicolumn{4}{|c|}{$\begin{array}{l}{ }^{a} \mathrm{p}<0.01 \text { for comparing Group } \mathrm{A} \text { and Group } \mathrm{B} ;{ }^{\mathrm{b}} \mathrm{p}<0.05 \text { for comparing Group } \mathrm{A} \text { and Group } \mathrm{B} \text {; } \\
{ }^{\mathrm{c} p}<0.01 \text { for comparing patients with nocturia (Groups } \mathrm{A}+\mathrm{B} \text { ) and patients without nocturia } \\
\text { (Group C); }{ }^{\mathrm{d} p}<0.05 \text { for comparing Groups } \mathrm{A}+\mathrm{B} \text { and Group C; AHI: apnea-hypopnea index, } \\
\text { IPSS: International Prostate Symptom Score. }\end{array}$} \\
\hline
\end{tabular}

coefficient: 0.104$)$, although a significant correlation was observed among patients who were $<50$ years old (correlation coefficient: $0.343 ; p=0.013$ ) (Fig. 2). Furthermore, when we compared the patients with OSAS and nocturia, Group A exhibited a significantly higher AHI, compared to Group B $(62.0 \pm 18.9$ vs. $47.8 \pm 17.9 ; p=0.013)$. Moreover, patients in Group A did not exhibit additional urination symptoms, especially voiding symptoms (Table 2 ).

\section{Urination status after CPAP treatment}

CPAP treatment significantly reduced the number of nighttime urinations (from $1.4 \pm 1.3$ to $0.7 \pm 0.9 ; p<0.01$ ), significantly improved the total IPSS (from $6.0 \pm 6.4$ to $4.3 \pm$ $5.1 ; \mathrm{p}<0.01)$, and significantly improved the total OABSS (from $2.7 \pm 2.6$ to $1.7 \pm 1.7 ; \mathrm{p}<0.01$ ). Moreover, $50 \%$ fewer patients reported urgent incontinence after CPAP treatment (Table 1). Among the 56 patients in Groups A and B, CPAP treatment significantly reduced the number of awakenings from $2.8 \pm 0.9$ times/night to $1.2 \pm 1.1$ times/night $(p<0.01)$. After CPAP treatment, the number of urinations was reduced in 48 of the 56 patients $(85.7 \%)$ with OSAS and nocturia before the CPAP treatment (12 patients in Group A [75\%] and 36 patients in Group B [90\%]). A significant difference was observed in the baseline OSAS severity when we compared patients with and without improved nocturia at three months after the CPAP treatment (AHI: $53.7 \pm 18.6$ vs. 37.3 $\pm 11.0 ; \mathrm{p}=0.042$ ).

\section{Discussion}

The present study revealed that nighttime urination was common among patients with OSAS and that patients with OSAS and nocturia tended to be older and have more severe OSAS (compared to patients with OSAS and without nocturia). The AHI was highest for $<50$-year-old patients with nocturia; these patients did not have additional urination

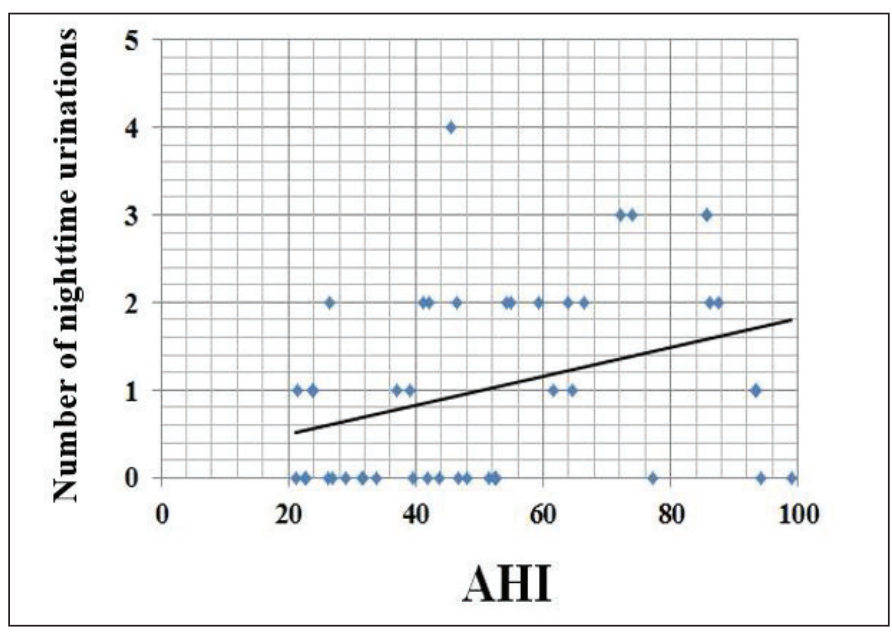

Fig. 2. Correlation of apnea-hypopnea index (AHI) with urinations among patients with obstructive sleep apnea syndrome and an age of $<50$ years.

symptoms, especially voiding symptoms. CPAP treatment decreased the incidence of nocturia in most patients and was most effective in patients with a severe AHI.

Previous reports have indicated that the prevalence of nocturia among patients with OSAS ( $\geq 2$ urinations per night) ranges from $40-50 \% .{ }^{17-19}$ The results of the present study are consistent with those findings and indicate that nocturia is a general symptom of moderate-to-severe OSAS. However, most patients (and even physicians) do not recognize the association between nocturia and OSAS. This lack of recognition is likely affected by the fact that nocturia is a common symptom among people $\geq 50$ years old and is associated with a variety of clinical syndromes and diagnoses, including hypertension, diabetes, obesity, benign prostatic hyperplasia, and coronary artery disease. . $^{13,14}$

Oztura et al reported that nocturia episodes were significantly more frequent among patients with sleep-related breathing disorders. ${ }^{20}$ Chen et al have also reported that nocturia is an independent predictor of severe obstructive sleep apnea in patients with ischemic stroke. ${ }^{21}$ In contrast, we found that the number of nighttime urinations was not correlated with OSAS severity when we considered all patients in the present study. However, Kang et al have reported that age-related urinary diseases and voiding dysfunction may mask the influence of OSAS and that OSAS may not be a risk factor for nocturia among elderly patients..$^{22}$ Our data are consistent with that finding, as OSAS severity was correlated with the number of nighttime urinations among patients who were $<50$ years old. We also observed that nocturia in $<50$-year-old patients with OSAS was not accompanied by other voiding symptoms. Therefore, OSAS should be considered a potential cause of nocturia in younger patients who do not have other voiding symptoms.

An accurate diagnosis of OSAS requires laboratory PSG, which is inconvenient and costly. Therefore, clinicians must 
select patients for PSG testing according to their specific risk factors. However, the symptoms of OSAS (e.g., excessive daytime sleepiness and fatigue) are subjective, rather than quantitative, and are difficult to precisely evaluate or use to screen for OSAS. Therefore, various clinical prediction models and questionnaires have been developed for detecting OSAS. For example, the Epworth Sleep Scale (ESS) uses eight simple questions, is widely available, provides high reliability, and can be performed quickly and easily to subjectively measure sleepiness. Although there are suitable associations between ESS scores and the severity of OSAS, the ESS is not useful when screening for OSAS, as it is not sensitive or specific for this purpose. ${ }^{23}$ Similarly, Morris et al reported that snoring severity and $\mathrm{BMI}$ are useful screening tools for OSAS, ${ }^{24}$ although it is difficult for the patient or their sleeping partner to precisely evaluate the degree of snoring. In contrast, the number of nighttime urinations is a simple quantitative parameter that can be monitored by both urologists and general physicians. Therefore, we believe that nocturia might be a useful tool for screening patients with moderate-to-severe OSAS, especially patients who are $<50$ years old.

Nakagawa et al have reported that nocturia can lead to both bone fracture and death. ${ }^{25}$ Moreover, treating nocturia is challenging and may result in only small improvements, as nocturia is a multifactorial condition. ${ }^{26}$ However, our data indicate that CPAP treatment significantly reduced the number of nighttime urinations from $2.8 \pm 0.9$ to $1.2 \pm$ 1.1 among patients with OSAS. Therefore, OSAS should be considered in the differential diagnosis of nocturia, as CPAP may effectively treat nocturia in patients with moderate-tosevere OSAS. Furthermore, CPAP treatment was effective in ameliorating other voiding symptoms (including urgent incontinence). Although the mechanism for this effect is unclear, improvements in hypoxic stress might positively affect the bladder's vascular endothelial cells.

There were several limitations in the present study. First, selection bias may have been introduced by selecting patients who visited a sleep clinic for OSAS treatment. Thus, prospective studies are needed to determine whether nocturia could be used to screen for OSAS in the general population. Second, the detailed mechanism for OSAS-induced nocturia is unclear, especially among patients who are $<50$ years old, although negative intrathoracic pressure can cause cardiac distention and the secretion of various vasodilators, which may increase urinary volume. Thus, future studies should incorporate frequency-volume charts, serum atrial natriuretic peptide levels, and the specific gravity of the morning urine before and after CPAP treatment, in order to better understand these patients' condition.

\section{Conclusion}

In $<50$-year-old patients with OSAS, the frequency of nocturia was correlated with the severity of OSAS and their nocturia was not accompanied by other voiding symptoms. CPAP treatment reduced the frequency of nocturia in patients with moderate-to-severe OSAS and this treatment may be most effective in patients with severe OSAS.

Competing interests: Dr. Asano has received honoraria from Astellas, Astra Zeneca, Bl, Kyorin, MSD, and Novartis; and has participated in clinical trials for BI and Teijin Pharma. The remaining authors declare no competing personal or financial interests.

Acknowledgement: This study was performed in accordance with the tenets of the Declaration of Helsinki and the ethical guidelines of the Japanese Ministry of Health, Labour, and Welfare.

This paper has been peer-reviewed.

\section{References}

1. Brooks D, Horner RL, Kozar LF, et al. Obstructive sleep apnea as a cause of systemic hypertension. Evidence from a canine model. J Clin Invest 1997;99:106-9. http://dx.doi.org/10.1172/JC1119120

2. Lavie $P$, Herer $P$, Hoffstein $V$. Obstructive sleep apnoee syndrome as a risk factor for hypertension: Population study. BMJ 2000;320:479-82. http://dx.doi.org/10.1136/bmi.320.7233.479

3. Ip MS, Lam B, Ng MM, et al. Obstructive sleep apnea is independently associated with insulin resistance. Am J Respir Crit Care Med 2002;165:670-6. http://dx.doi.org/10.1164/airccm.165.5.2103001

4. Polotsky VY, Patil SP, Savransky V, et al. Obstructive sleep apnea, insulin resistance, and steatohepatitis in severe obesity. Am J Respir Crit Care Med 2009;179:228-34. http://dx.doi.org/10.1164/ rccm.200804-6080C

5. Yalamanchali S, Farajian V, Hamilton C, et al. Diagnosis of obstructive sleep apnea by peripheral arterial tonometry: Meta-analysis. JAMA Otolaryngol Head Neck Surg 2013;139:1343-50. http://dx.doi. org/10.1001/jamaoto.2013.5338

6. Seetho IW, Wilding JP. Screening for obstructive sleep apnoea in obesity and diabetes-potential for future approaches. Eur J Clin Invest 2013;43:640-55. http://dx.doi.org/10.1111/eci.12083

7. Tregear $S$, Reston J, Schoelles K, et al. Obstructive sleep apnea and risk of motor vehicle crash: Systematic review and meta-analysis. J Clin Sleep Med 2009;5:573-81.

8. Lavie L. Oxidative stress - a unifying paradigm in obstructive sleep apnea and comorbidities. Prog Cardiovasc Dis 2009:51:303-12. http://dx.doi.org/10.1016/i.pcad.2008.08.003

9. Nacher $M$, Serrano-Mollar A, Farre $R$, et al. Recurrent obstructive apneas trigger early systemic inflammation in a rat model of sleep apnea. Respir Physiol Neurobiol 2007;155:93-6. http://dx.doi.org/10.1016/i. resp.2006.06.004

10. Ip MS, Tse HF, Lam B, et al. Endothelial function in obstructive sleep apnea and response to treatment. Am J Respir Crit Care Med 2004;169:348-53. http://dx.doi.org/10.1164/rccm.200306-7670C

11. Young T, Palta M, Dempsey J, et al. The occurrence of sleep-disordered breathing among middle-aged adults. N Engl J Med 1993;328:1230-5. http://dx.doi.org/10.1056/NEJM199304293281704

12. Nakayama-Ashida $Y$, Takegami $M$, Chin $K$, et al. Sleep-disordered breathing in the usual lifestyle setting as detected with home monitoring in a population of working men in Japan. Sleep 2008;31:419-25.

13. Yoshimura K, Terada N, Matsui Y, et al. Prevalence of and risk factors for nocturia: Analysis of a health screening program. Int J Urol 2004;11:282-7. http://dx.doi.org/10.1111/i.1442-2042.2004.00791.x

14. Bing MH, Moller LA, Jennum $P$, et al. Nocturia and associated morbidity in a Danish population of men and women aged 60-80 years. BJU Int 2008;102:808-14; discussion 14-5. http://dx.doi. org/10.1111/.i.1464-410X.2008.07813.x

15. Sleep-related breathing disorders in adults: Recommendations for syndrome definition and measurement techniques in clinical research. The report of an American Academy of Sleep Medicine Task Force. Sleep 1999;22:667-89 
16. Homma Y, Yoshida M, Seki N, et al. Symptom assessment tool for overactive bladder syndrome overactive bladder symptom score. Urology 2006;68:318-23. http://dx.doi.org/10.1016/i.urology.2006.02.042

17. Hajduk IA, Strollo PJ, Jr., Jasani RR, et al. Prevalence and predictors of nocturia in obstructive sleep apnea-hypopnea syndrome-a retrospective study. Sleep 2003;26:61-4.

18. Guilleminault C, Lin $C M$, Goncalves $M A$, et al. A prospective study of nocturia and the quality of life of elderly patients with obstructive sleep apnea or sleep onset insomnia. J Psychosom Res 2004;56:511-5. http://dx.doi.org/10.1016/S0022-3999(04)00021-2

19. Moriyama Y, Miwa K, Tanaka $H$, et al. Nocturia in men less than 50 years of age may be associated with obstructive sleep apnea syndrome. Urology 2008;71:1096-8. http://dx.doi.org/10.1016/i.urology.2008.02.038

20. Oztura I, Kaynak D, Kaynak HC. Nocturia in sleep-disordered breathing. Sleep Med 2006;7:362-7. http:// dx.doi.org/10.1016/i.sleep.2005.10.004

21. Chen $\mathrm{CY}$, Hsu CC, Pei YC, et al. Nocturia is an independent predictor of severe obstructive sleep apnea in patients with ischemic stroke. J Neurol 2011;258:189-94. http://dx.doi.org/10.1007/s00415010-5705-2
22. Kang SH, Yoon IY, Lee SD, et al. The impact of sleep apnoea syndrome on nocturia according to age in men. BJU Int 2012;110:E851-6. http://dx.doi.org/10.1111/i.1464-410X.2012.11342.x

23. Kapur VK, Baldwin CM, Resnick HE, et al. Sleepiness in patients with moderate to severe sleep-disordered breathing. Sleep 2005;28:472-7.

24. Morris LG, Kleinberger A, Lee KC, et al. Rapid risk stratification for obstructive sleep apnea, based on snoring severity and body mass index. Otolaryngol Head Neck Surg 2008;139:615-8. http://dx.doi. org/10.1016/i.otohns.2008.08.026

25. Nakagawa H, Niu K, Hozawa A, et al. Impact of nocturia on bone fracture and mortality in older individuals: A Japanese longitudinal cohort study. J Urol 2010;184:1413-8. http://dx.doi.org/10.1016/i. juro.2010.05.093

26. Weiss JP, Blaivas JG. Nocturia. Curr Urol Rep 2003;4:362-6. http://dx.doi.org/10.1007/s11934003-0007-1

Correspondence: Dr. Koichi Fukunaga, Division of Pulmonary Medicine, Department of Medicine, Keio University School of Medicine, Tokyo, Japan; km-fuku@cpnet.med.keio.ac.jp 